The patient made good progress and was sent to a con valescent institution on July 8 th.

Subsequently to the operation the following history was elicited. The patient was 47 vears of age and single. Some two years ago she had retention of urine following a strain. She stated that she did not pass urine for three days, when 86 ounces were taken away by catheter. On another occasion 66 ounces were removed. Since that time she had used a catheter herself for attacks of retention. The menstrual periods had lately become more frequent and more profuse, with irregular discharges of blood, but none of any other kind. In July, 1898, she first noticed a "swelling" inside which seemed to come down on straining to pass urine or in having the bowels moved. She then attended a hospital in London and was advised to wait before anything could be done. She had had little pain except when the attacks of retention occurred. Her general health had been feeble out she continued at work as a servant.

The case is interesting as showing how so large a growth may exist without active treatment and with comparatively little distress and the sudden onset of symptoms necessitating immediate removal. The differential diagnosis in these cases appears to rest not so much upon the question of inversion as upon inversion complicated with attached fibroid-a much more difficult connexion in some cases to decide clearly. It is not common for growths of this kind to develop from the cervical lip; generally they are extruded from the interior of the uterus. Certain localised growths of the uterine walls I believe sometimes alter their position. It would be interesting to ascertain if, originally arising in the uterine wall, the direction and development could be made towards and through the substance of the cervix.

Birmingham.

\section{A CASE OF HERNIOTOMY IN A SEPTUAGENARIAN FOLLOWING IMMEDIATELY ON AN ATTACK OF HYPOSTATIC PNEUMONIA.}

By T. Wilson Parky, M.A., M.B., B.C. Cantab.

ABout Nov. 22nd, 1898, I was sent for to see a widow, 74 years of age, who, her friends told me, had been ailing for some days and had been obliged to take to her bed. I found her breathing heavily and looking very ill. I examined her carefully and discovered on putting my ear to her back râles over both chests and on percussion there was definite dulness over both bases. I write these facts from memory, as I took no notes of the case, considering them at that time to be unimportant and uninteresting from a recording view-point. Her temperature, as far as I can remember, never mounted above $103^{\circ} \mathrm{F}$. I need hardly state that I at once propped her up in bed and I prescribed for her a mixture containing ipecacuanha wine, carbonate of ammonia, and tincture of cinchona. One feature of interest was attached to this part of the case-viz., she refused food. I had recourse, therefore, to what I have found to be of great advantage in country practice among villagers who become stubborn on this point. I have frequently noticed that when an old person falls sick the sympathising friends and relations consider it an unkind thing to trouble the patient to take food if it is not wished for ; consequently, in some instances, a patient's friends do their best, quite unconsciously, to starve their unfortunate relation to death. Happily, however, for the patient in question I was called in in time. I insisted that if she did not take her food by the mouth she should have it by the rectum. Upon this the patient made the required effort and took that amount of food and stimulant which I considered necessary for her in the orthodox manner, and eventually, after some weeks of patient watching and nursing, she slowly got better. On Jan. 8th, 1899, I called upon her and found her so far improved as to be able to say that I thought it unnecessary for me to see her again but that she was to let me know at once if she were not so well. On the very next day, at about 9 P.M., I was sent for urgently as the patient was in great pain. I went at once and to my astonishment found that she had got a strangulated femoral hernia on the right side. She had been sick several times and she had great pain in the right groin. I tried careful taxis but failed to reduce the hernia. There was no ice to be had in the place, so I had to content myself by filling an icebag with cold water, raising the foot of the bed and applying the ice-bag to the groin, relieving her of its weight as far as possible by slinging it from a fixed point above. As I was single-handed I despatched a messenger for medical assistance and Dr. Knox of Bakewell kindly came over and gave chloroform for me. After repeating taxis under the anæsthetic and again failing I cut down, incised Hey's and Gimbernat's ligaments, and reduced the rupture without opening the sac. In the after treatment I was, of course, obliged to keep the patient propped up in bed during the whole time to avoid a relapse of the hypostatic congestion, and I am glad to say that she made a very satisfactory though somewhat tardy recovery. The point of interest in this case is that a woman who had passed the proverbial "three score years and ten" should successfully survive two such serious illnesses, either of which was easily sufficient to cost her her life, and the fact of the one following so immediately in the wake of the other with such excellent results makes it, to my mind, doubly interesting and satisfactory.

Yonlgreave.

\section{A FOREIGN BODY IN THE RECTUM.}

By JAMes S. MarTin, M.B. Edin., M.R.C.S. EnG., HOUSE SURGION, ROTHERHAN HOSPITAT.

THE presence of large foreign bodies in the rectum, though not very uncommon, is sufficiently so to warrant a brief notice of such a case when it occurs.

A patient who was admitted into the Rotherham Hospital on July 9th, 1899, stated that he had a glass bottle in the rectum which had got fixed there when he had sat upon it. On examination the base of the bottle could be felt by the finger in the middle part of the rectum. It lay with the base in the hollow of the sacrum and was freely moveable. The top could be felt to impinge upon the sacral promontory. It did not convey to the finger any impression of its true size and one or two ineffectual attempts were made to remove it without an anæsthetic. Afterwards chloroform was given and the bottle was extracted with midwifery forceps as it was too large to allow of its being brought through by the hand. It was a thick glass bottle three inches in height, with a circumference of six inches and a diameter of two inches. The neck of the bottle was conical. The patient went home on the next day feeling quite well.

The true history of the case would appear to be that the patient had been intoxicated in the presence of five or six friends who had inserted the bottle as a practical joke.

I am indebted to Mr. Lyth, under whose care the patient was, for permission to publish the case.

Rotherham.

British Dental Assoctation.-The annual meeting of the Western Counties Branch of the British Dental Association was held at Weymouth on July 21st and 22nd. The President, Mr. W. A. Hunt, L.R.C.P. Lond, M.R.C.S. Eng., delivered an interesting address and papers were read by Mr. Thompson, Mr. Taylor Genge, and the President. The report showed that the members now numbered 83 and that there was a favourable balance of $£ 24$. The annual dinner took place at the Royal Hotel in the evening. On July 22nd there was an excursion to Sherborne Castle. It was decided that next year's meeting should be held at Bristol and Mr. H. Helyar of Yeovil was nominated as President.

Medical Fees under the PoOR-Law.-At a recent meeting of the St. Germans Board of Guardians (Cornwall) it was stated that Mr. Gill, the medical officer of the St. Germans district, claimed £5 for attendance upon a parish patient. It appeared that the patient was a member of a friendly society of which Mr. Gill was the surgeon and that he suffered from a compound fracture of the leg. During the illness the man became a parish patient, receiving parish relief, and as he resided in Mr. Gill's district the extra fee was claimed. A considerable discussion arose as to whether the club or the guardians were liable for the medical attendance, as the surgeon had received no order from the relieving officer to attend the man. The guardians eventually decided by 13 votes to 11 to pay the fee. 